\title{
A Study on the Perception of Elderly Well-Dying Using Q-methodology
}

\section{IJCRR}

Section: Healthcare

Sci. Journal Impact

Factor: 6.1 (2018)

ICV: 90.90 (2018)

\section{MeeSuk Wang ${ }^{1}$, SooOk Kim²}

'Department of Nursing, Hanseo University, 46 Hanseor Ro, Haemi-myun, Seosan-si, Chungcheongnam-do, 369-709, Korea; ${ }^{2}$ Department of Nursing, Chunnam Techno University, 113, Daehak-ro, Okgwa-myeon, Gokseong-gun, Jeollanam-do, 516-911, Korea.

\section{ABSTRACT}

Introduction: This paper is the increase of old population and expansion of life span, various education programs for the elderly have been performed in elderly schools and senior welfare centres. Those programs must include contents on the perception of well-dying and preparation for well-dying.

Aim and Objective: This study helps us to grasp the subjectivity and the characteristics of each type of how Korean elderly perceive good death. By applying the $Q$ methodology, 31 elderly aged 65 or older living in $G$ metropolitan city were selected as a convenient sampling method to classify 28 sentences of well-dying. Data were collected by distributing 28 selected $Q$ samples on a $Q$ distribution on a 9-point scale. Collected data were analyzed by $Q$ factor after making data-file. The collected data scored the conversion points assigned to each of -4 with 1 point, 5 points neutral, and 9 points +4 with cards forcibly distributed on the $Q$ sample distribution table. By coding the given conversion scores in order of $Q$ sample number, Using $P Q$ method. As a result, the well-being perceived by the elderly was recognized as three types of Type1 is 'accepting death', Type 2 is 'preparing death' and Type 3 is 'peaceful death'.

Conclusion: The results of this study will be used as a basis for developing a more in-depth well-dying education program, specific and differentiated well-dying education is needed based on the perception of the death of the elderly and interventions from the perspective of the elderly to prepare for well-dying. It is hoped that, In the future, more research using the findings of this research, and based on the survey on the perception of well-dying among different age groups will be made, and educational programs will be developed.

Key Words: Well-dying, Perception, Elderly, Q - methodology

\section{INTRODUCTION}

In Korea, people aged 65 or older entered the ageing society with $14.3 \%$ of the elderly in 2018 and more than $20 \%$ expected to become a super-aged society in 2025(Statistics Agency, 2019). This ageing population and the increasing number of elderly people are increasing social interest in how to live life and how to prepare for death. Death is the universal and natural order of man, but awareness of death is an extremely personal and subjective experience that is difficult to reasonably understand ${ }^{1}$ and should be approached in consideration of the period and cultural characteristics. It was also shown that most humans have anxiety and fear about death, especially those of elderly people who are close to death, which degrades the quality of life in old age ${ }^{2}$. How to die, is an addition to be aware of it, a mature human at- titude, is to accept it as one's work. Try to understand its meaning without ignoring it or evading it in front of the fear of death. A task that must be accomplished in all life processes $^{3,4}$.

\section{BACKGROUND OF STUDY}

Erikson(1963) said that an old man who achieved self-integration, a developmental task in his old age, embraces his life and easily accepts death. The elderly, especially those close to death, are increasingly interested in when and how they die rather than death itself, which has increased their interest in well-dying socially ${ }^{5}$. Whether it is a death that comes naturally to an old man or a sudden death that comes to a young man, death is a part of life that everyone needs

\section{Corresponding Author:}

Dr. SooOk Kim, Department of Nursing, Chunnam Techno University, 113, Daehak-ro, Okgwa-myeon, Gokseong-gun, Jeollanam-do, 516911, Korea; E-mail: sokim@chunam-c.ac.kr

ISSN: 2231-2196 (Print)

Received: 15.06 .2020
ISSN: 0975-5241 (Online)

Revised: 10.07 .2020
Accepted: 18.07 .2020 
to prepare for. In addition to how to perceive death, it is a mature human attitude to try to understand the meaning of it by not accepting it or evading it in front of the fear of death ${ }^{3}$.

Recently in Korea, the "Hospice Medical Reducing and Deciding the Life and Life Care of Patients in the End-oflife Process," called the Well-Dying Act, passed the plenary session of the National Assembly in January 2016, and it was to go into effect in February 2018. The Well-Dying Act respects the right to self-determination of death and decides on one's life insurance. This change in perception of death has raised social interest and demand for well-dying ${ }^{6}$, and the question of withdrawal of life-sustaining treatment has become more about good deaths that anyone can prepare for themselves. It was found that the elderly were considered to have a good lifespan suitable for the condition of a good death, a soldier without a soldier, dying before a spouse or offspring, not bothering the offspring, and dying in front of the whole family ${ }^{3}$. So, to prepare for the future situation, it is suggested to apply for a pre-medical intent or to give children medical treatment for themselves as a will. From the point of view that prioritizes the dignity of each patient, rather than the meaningless extension of life, the right to self-determination for quality of life and decent death is emphasized ${ }^{7,8}$. It is increasing. Well-dying has the meaning of comfortable death, a good death, and decent

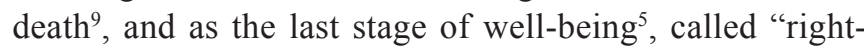
ful death" rather than a "just waiting death." right to die with dignity, and the dignity of death is realized through death with dignity. The term "well-ageing," means from "well-being,", "living well", to "get old", and it also replaces "well-endings", which means good endings ${ }^{11}$. Well-dying is to die a decent death through the preciousness of life, to look back on one's own life and find the true value of life through the preparation of death. The person preparing for death has a positive attitude toward life and death $^{3,12,13}$.

Among scholars in Korea and foreign countries, there have been several researchers on conditions of well-dying investigated the ideas of well-dying among patients, family members of those patients and the medical team in the hospice $^{14,15}$ referred to literature review to induce three core elements for well-dying preparation for death, no pain, and emotional stability ${ }^{16,17}$ are the findings from the survey on well-dying to nursing school students and nurses ${ }^{18}$ is the research on the perceptions of well-dying among old people in rural areas; ${ }^{19}$ suggests 6 definitions on well-dying ${ }^{20,21}$ are on the experiences of getting old ${ }^{23}$ classifies perception types on well-dying among middle-aged and old aged people using latent class analysis (LCA) ${ }^{24}$ is on well-dying and family support among in-house old people. It is an analysis of socio-demographic characteristics using descriptive statistics and cross-tabulation analysis. Most of the exist- ing researches on well-dying have been on definitions of well-dying, literature review, and survey analyses. There was qualitative research asking old people on well-dying ${ }^{20}$. It is difficult to find out the meaning of well-dying among old people in various social conditions from such researches. They have limits in revealing innermost thinking of old people.

As the perception of well-dying can change over time, it will be very meaningful to provide old people preparing for well-dying with high-quality nursing care. Thus, it is necessary to examine the definitions of well-dying in Korea and differences and common aspects between the concept of well-dying and similar concepts. Nobody can avoid death, and everybody wants to die well. Therefore, it is necessary to examine the attributes of well-dying. In particular, to old people, well-dying gives many meanings to their belief and value systems, and their daily lives. Each of the elderly needs to understand and prepare for well-dying.

Since the old man's perception of well-dying is associated with the old man's quality of life, preparation for well-dying is essential in his old age ${ }^{25}$. Well-dying education is currently being conducted in welfare centres and senior colleges, and specific and differentiated well-dying education is needed based on the perception of the death of the elderly. So it is necessary to understand what well-dying is perceived by the old man. However, well-dying is a subjective phenomenon experienced by the background and cultural characteristics of an individual's life, and it is not easy to approach in general research ${ }^{26}$.

Thus, this research tried to individual subjective views on well-dying through the survey on subjective perception on well-dying among old people, and, to identify the individual differences in such a perception among respondents, it used Q methodology. Now is the time in Korea to analyze welldying types and deal with different types with proper measures, this research was performed to help people to establish and understand the concepts of well-dying.

\section{METHOD}

\section{Design}

To achieve the purpose of the study, we examine the literature, media data, and preceding research on well-dying and discover the subjectivity of seeing the type of subjective perception of well-dying for the elderly. The method invented by Stephenson is an objective measure of the attitude or subjectivity of an individual to a particular object ${ }^{15}$. To classify well-dying types and examine the characteristics of each type, this research used Q methodology. Q-sort acquired from the sorting process was under Q-factor analysis using the PC QUANAL program. 


\section{Research procedure}

\section{- Selecting Q samples and P samples}

Q population was derived through domestic and foreign literature review, open questionnaires, and in-depth interviews to extract comprehensive statements about well-dying recognized by the elderly at present. To collect various opinions on well-dying, the purpose of this research was explained to the elderly aged 65 or older and then extracted the elderly who wanted to participate with interest. The research extracted 150 sentences from the literature review, and another set of 100 sentences from the interviews to old people. The 250 sentences related to well-dying were extracted to 100 sentences with the help of 2 nursing professors, $2 \mathrm{Ph}$. D students in nursing science, and 2 old people. These 100 sentences were used for the pre-test applied to 7 old respondents, and, finally, this research chose 30 sentences out of 100. Afterwards, 2 out of the 30 sentences were eliminated, because they were found to repeat other sentences. Finally chosen 28 sentence Q sample were made to be allocated equally in positive, neutral, and negative expressions.

To select the Q sample in this study, the final 28 Q samples with high discrimination were selected after reviewing and revising the procedures of one Q methodology expert, three nursing professors, two master's students and five senior citizens.

Q-methodology is a qualitative research study that emphasizes the subjectivity of individuals by focusing on differences in meaning or importance within individuals, not on differences between individuals. As the P sample is larger, 31 people are common because it is based on the small sample doctrine that multiple people are biased against a factor and its characteristics are not revealed. Sample P from this study presented convenience to 31 senior citizens who agreed to participate in the study. Among them, 31 were subject to the final study, except for one who gave up due to personal reasons $^{27}$.

\section{Data collection and method of $\mathbf{Q}$ samples}

Q sample design and Q sample selection are completed, each respondent (Q-sorter) selected to be part of the Q sample is asked to classify Q sample, which is called Q-sorting. Qsorting is to make each respondent himself or herself a model by revealing his or her attitudes on complex subjects or issues. After reading statements, each respondent selects his or her choices on them, leading those choices to belong to forced normal distribution.

Respondents of this survey were those who were 65 years old or above residing in Jeolla province, who had no problem in linguistic communication and do not have orientation disturbance, and who agreed to participate in the survey. Respondents were selected by convenience sampling method.
They agreed to participate in the survey in written form, the researcher or the research assistant met each of them, gave him or her Q card, asking the respondent to do Q-sorting. If the respondent had difficulty in Q-sorting, the researcher or the research assistant read the statements and asked him or she does Q-sorting, and the researcher or the research assistant marked the respondent's choice on the Q card. While the interview was conducted to 35 respondents, 4 of them quit answering the interview, or could not understand some of the statements. Accordingly, 31 copies of the questionnaire were finally used for analysis.

The classification of Q samples is the process of forcibly distributing the extracted Q samples in the Q sample distribution table, using the principle of the Q methodology to approximate the normal distribution. If necessary, later interviews were conducted, after Q-sorting was done. First, after reading the 28 samples prepared, the cards most similar to their views were forcedly distributed to 2 positive $(+4)$, neutral (0) 5, and positive-negative (-4). After that, the resulting score was 9 points for +4 , then $8,7,6$, the neutral score was 5 points, -4 for 1 point, and then 2,3,4 points[Table 1].

The Q classification process is a process in which the subjects selected as $\mathrm{P}$ sample form a self-determination definition of a good death by classifying the statements in the Q sample as forced normal distribution method. The location for collecting data was selected as the desired location for the target, such as a conference room or lounge area, which can be quiet and maintain the participants' privacy, and the time was chosen as the desired time without any disturbance to the fatigue level of the subject. The target person collected the data using a Q card for the elderly who were conscious, able to communicate, and agreed to the study. It took 30 to 50 minutes for one person to complete the Q-classification.

\section{Data analysis}

The collected data scored the conversion points assigned to each of -4 with 1 point, 5 points neutral, and 9 points +4 with cards forcibly distributed on the $\mathrm{Q}$ sample distribution table. By coding the given conversion scores in order of $\mathrm{Q}$ sample number, the main factor analysis was done using PQ method. The mean and standard deviation of types were analyzed using the SPSWIN 21.0 program.

\section{Ethical considerations}

It explained to the study that it could be stopped at any time during the study after obtaining voluntary consent before the study and that there were no disadvantages. It explained that the collected data will be used only for research purposes and that personal information will be kept confidential. Also, to respect the rights of the subjects and to ensure the privacy and personal information of the subjects, all information collected through this study was kept confidential and coded 
throughout the entire data analysis process to ensure the confidentiality of the subjects.

\section{RESULTS}

Characteristics of different types of perceptions on well-dying among old people were analyzed. The analysis of subjectivity of perceptions on well-dying of old people was found three types.

\section{Types of well-dying recognized by the elderly}

\section{Structure of Q type}

An analysis of the subjectivity of well-dying recognized by the elderly showed three types.

\section{Type of well-dying recognized by the elderly}

To analysis by type the subjectivity of well-dying recognized by the elderly, type-specific characteristics were first described around statements belonging to each type. The Q response of the $\mathrm{P}$ sample (Study Participant) was divided into the top and bottom questions and two factors were extracted. Q Methodology indicates which type of person belongs to each type is typical or ideal, the person with a higher factor weight. Among the subjects, there were 11 persons the first type, 12 persons in the second type, and 8 persons in the third type. General characteristics of types,

In age distribution, $64.5 \%$ to the age group from 75 to 84 and $74.2 \%$ were females. In religiosity, $45.2 \%$ were Protestants, the largest group. While $93.5 \%$ were married [Table 2].

To analysis the characteristics of each type of statement about well-dying, the meaning was read by focusing on statements with a $\mathrm{z}$-score of \pm 1.00 or higher. In this study, 11 persons with a factor weight of 1.0 or higher were included in the first type, 12 persons were included in the second type, and 8 persons were included in the third type[Table 2].

To classify subjectivity perceived by old respondents into types, this research first described characteristics of each type based on statements belonging to each type. Q responses to Q sample (research participants) were divided into the upper questions and lower questions, and 2 factors were extracted. In Q methodology, among those belonging to a certain type, the one whose factor weight is higher than those of others is considered as the typical or ideal person. In the data set of this research, the number of respondents whose factor weights are over 1.0 is 3 in factor 1, 4 in factor 2, and 1 in factor 3 .

To analyze characteristics of each type related to well-dying, this research interpreted them using the statements whose zscores are over \pm 1.00 .
Table 1: Distribution of Q-Population( $(\mathrm{N}=31)$

\begin{tabular}{lccccccccc}
\multicolumn{10}{c}{ Disagree Neutral Agree } \\
Score & $\mathbf{1}$ & $\mathbf{2}$ & 3 & 4 & 5 & 6 & 7 & $\mathbf{8}$ & $\mathbf{9}$ \\
Frequency & -4 & -3 & -2 & -1 & 0 & 1 & 2 & 3 & 4 \\
(Amountof & $(1)$ & $(3)$ & $(4)$ & $(5)$ & $(6)$ & $(5)$ & $(4)$ & $(3)$ & $(1)$ \\
Q-samples) & & & & & & & & & \\
\hline
\end{tabular}

The data were analysed using Q-factor analysis, in particular, principal factor analysis. Types were selected with the criteria of eigenvalue 1.0 or over. An analysis of the subjectivity of well-dying in older people is categorized into three types. Accounting for $40.31 \%$ of the total valuation, the first type was $5.862 \%$, the second type was 3.950 . Variates are $18.9 \%, 12.7 \%$, and $8.6 \%$ respectively. The data showed. The primary factor has an explanatory power of 5.862, which can be seen as the reason why older people describe well-dying the most of the 31 surveyed, 11 were identified as the first type, 12 as the second type and eight as the third type. In this study, high and low questions were grouped for the three types of recognition of well-dying for the elderly [Table 3].

The correlation coefficient between the three factors shows the degree of similarity between each type, in three types the correlation coefficient of type 1 and type 2 is .136, type 1 and type 3 are -.273 , Type 2 and Type 3 are -.419 . Type 2 and type 3 indicated a relatively high negative correlation compared to other types, and type 1 and type 3 represented a positive correlation [Table 4]. Correlation coefficients demonstrate that each type is independent of each other. Type 1 and type 2 can be said to be most distinct. However, the correlation between factors in $\mathrm{Q}$ method focuses on finding factors without assuming complete independence between each factor. No controversy is raised about the method of extracting factors due to high and low correlation [Table 3].

In the $\mathrm{P}$ sample consisting of 31 respondents, 11 belonged to type 1,12 to type 2 , and 18 to type 3 . Among the respondents belonging to each type, the one whose factor weight is the highest is considered to represent the type.

\section{Table 2: Sociodemographic and clinical characteris- tics of participants $(\mathrm{N}=31)$}

$\begin{array}{lr}\text { Characteristics } & \text { Value } \\ \text { Age } & \\ \text { Mean } & 75 \cdot 4 \\ 65-74 \text { years } & 35 \cdot 5 \\ 75-84 \text { years } & 64 \cdot 5 \\ \text { Sex }(\%) & \\ \text { Male } & 25.8 \\ \text { Female } & 74.2 \\ \text { Religious affiliation(\%) } & \end{array}$


Table 2: (Continued)

\begin{tabular}{lc} 
Characteristics & Value \\
Roman Catholic & 16.1 \\
Protestant & 45.2 \\
Atheist & 38.7 \\
Marital Status(\%) & \\
Single & 6.5 \\
Married & 93.5 \\
Education(\%) & \\
$\geq$ Middle school & 38.7 \\
High school & 32.3 \\
College or University & 29 \\
\hline
\end{tabular}

Table 3: Eigen Value, Variance, and Cumulative Percentage

\begin{tabular}{lccc} 
& Type I & Type II & Type III \\
Eigen Value & 5.862 & 3.950 & 2.681 \\
Variance (\%) & 18.9 & 12.7 & 08.6 \\
Cumulative & .469 & .316 & .403 \\
\hline
\end{tabular}

Table 4: Correlations Between Type Scores

\begin{tabular}{lccc} 
& Type I & Type II & Type III \\
Type I & 1 & & \\
Type II & .136 & 1 & \\
Type III & -.273 & -.419 & 1 \\
\hline
\end{tabular}

\section{Analysis per types}

The types of well-dying recognition for older adults calculated by this type of analysis method are as follows[Table 5].

\section{Acceptable death}

The "acceptable death" classified as the first type consisted of 11 people (table 4). The most positive aspects of the first type analysis and the first type were that "well-dying" was to return to religion and embrace God with joy (1.87) and "well-dying was to die without regret and obsession" (1.43)."Well-dying is knowing that death is not the end, it lives forever (1.505)."Well-dying has no regrets about the day he has lived" (.886). "Well-dying is to die at home without being hospitalized for a long time" (.707). "The most negative aspects of the first type appeared so that well-dying was death" (-1.75) "leaving property or belongings to his children, and that he was prepared for death" (-1.72). "Welldying is the emancipation and resting place of the hard life in this (-1.67). "Well-dying is that my friends are mourning the death"(-1.59). "Well-dying will shorten the disease of old age and die peacefully"(-1.39). In the first type, the highest factor weights were shown in the order of No. 26
(2.266), No. 28 (1.612), and No. 30 (1.054). The lowest factor weights were shown in the order of subject No. 7 (.236) and No. 20 (.446). The subject No. 26 said, "Well-dying is in God's arms and well-dying is to be settled without regret". The subject No. 30 said, "Well-dying is usually a good religious life and I believe in resurrection". Therefore, the first type was named "acceptable death", which accommodates the first type.

\section{Prepared death}

The "preparing death" classified as Type 2 consisted of 12 persons(table 4). after analyzing type 2 The most positive information of the second type was that "well-dying was to be prepared in advance knowing that it was time to die" (1 (1.75) and "well-dying was accepted as a fateful process of life as a raw old soldier" (1.69). "Well-dying is a leisurely and dignified deadline for a peaceful death by organizing life"(1.58). "Well-dying will shorten the disease of old age and die peacefully"(1.39). "Well-ding recognizes the natural principle of the cycle of death"(1.24). The most negative thing about Type 2 was that "people around them died painlessly" (-1.61). "Well-dying is to die at home without being hospitalized for a long time"(-1.49). "Well-dying is living a healthy life and then dying painlessly"(-1.37). "Well-dying is a death that leaves property or heritage for children"(-1.34). "Well-dying is a natural death without life extension or treatment"(-1.16). The subjects with the highest factor weighting in Type 2 were No. 13 (1.740), No. 15 (1.553), and No, 5 (1.300). The subject No. 13 said, "Well-dying is to live in peace, organizing your life normally and To live in preparing for well-dying". The subject No. 15 said, "Well-dying is not obsessed with matter and I don't leave my property to your children, I leave only souvenirs."Therefore, the second type was named "Death preparation".

\section{Peaceful death}

The "Peaceful death" classified as the third type consisted of eight people (table 4). The analysis of the third type showed that the most positive aspects of the third types were "Welldying is to die at home without being hospitalized for a long time" (2.35) and "Well-dying is a natural death without life extension or treatment" (2.20). "Well-dying is when people around you die painlessly" (1.40), "Well-dying is a death with a sense of time and grace to organize life and meet peacefully" (1.00), "Well-dying is to die at home without being hospitalized for a long time"( 0.87$)$. The most negative aspect of the third type is that "Well-dying is to live and die without the support of children or others" (-1.49), "Welldying is a haven for death" (-1.33), "Well-dying is to come blessed and return to where you came from"(-1.29), "Welldying is a death that leaves property or heritage for children" (-1.18), "Well-dying is that my friends are mourning the death" (-1.15) shown in order. The subjects with the highest 
factor weights in the third type were No. 27 (1961), No. 9 (.906), and No.19 (.834). The subjects with the lowest factor weight were No. 14 (.263) and No. 8 (.322). The subject No. 27 said, "Well-dying is painfully not dead on hospital bills and Living in a house and dying peacefully". The subject No. 9 said, "Well-dying is not life-extending and Well-dying is a death that is not painful even for those around me". Therefore, the third type was named Peaceful Death.

Table 5: Q-statements on Well-dying type of representative items and Z-scores. ( $N=31)$

\begin{tabular}{|c|c|c|c|c|}
\hline \multicolumn{5}{|c|}{ Representative items of type } \\
\hline Type & $\begin{array}{l}\text { Item } \\
\text { no }\end{array}$ & Representative items & Mean(SD) & Z-score \\
\hline \multirow[t]{10}{*}{$\begin{array}{l}\text { Type1 } \\
(\mathrm{N}=11)\end{array}$} & 21 & $\begin{array}{l}\text { Well-dying is to return to religion and embrace it in the arms of God } \\
\text { with joy. }\end{array}$ & $3 \cdot 37( \pm 1.302)$ & 1.87 \\
\hline & 20 & Well-dying is to die without regret and obsession. & $2.87( \pm 1.807)$ & 1.43 \\
\hline & 13 & Well-dying is knowing that death is not the end, it lives forever. & $4.62( \pm 1.505)$ & 1.20 \\
\hline & 17 & Well-dying has no regrets about the day he has lived. & $3.75( \pm 0.886)$ & 1.05 \\
\hline & 28 & $\begin{array}{l}\text { Well-dying is to die at home without being hospitalized for a long } \\
\text { time }\end{array}$ & $6.75( \pm 0.707)$ & 1.00 \\
\hline & 9 & Well-dying will shorten the disease of old age and die peacefully & $4.25( \pm 0.707)$ & -1.39 \\
\hline & 14 & Well-dying is that my friends are mourning the death & $3.12( \pm 1.885)$ & -1.59 \\
\hline & 8 & $\begin{array}{l}\text { Well-dying is the emancipation and resting place of hard life in this } \\
\text { world. }\end{array}$ & $3.12( \pm 0.640)$ & -1.67 \\
\hline & 3 & Well-dying is about preparing for death in advance. & $2.37( \pm 0.916)$ & -1.72 \\
\hline & 23 & $\begin{array}{l}\text { Well-dying is a death that leaves its children with property or belong- } \\
\text { ings }\end{array}$ & $2.62( \pm 1.187)$ & -1.75 \\
\hline \multirow{10}{*}{$\begin{array}{l}\text { Type2 } \\
(\mathrm{N}=12)\end{array}$} & 3 & Well-dying is about preparing for death in advance. & $3 \cdot 50( \pm 1.690)$ & 1.75 \\
\hline & 2 & Well-dying is an acceptance of life as a fateful process of life and death. & $4 \cdot 75( \pm 1.164)$ & 1.69 \\
\hline & 10 & $\begin{array}{l}\text { Well-dying is a leisurely and dignified deadline for a peaceful death by } \\
\text { organizing life }\end{array}$ & $4.87( \pm 0.991)$ & 1.58 \\
\hline & 9 & Well-dying will shorten the disease of old age and die peacefully & $4.25( \pm 0.707)$ & 1.39 \\
\hline & 11 & Well-ding recognizes the natural principle of the cycle of death & $4.62( \pm 1.505)$ & 1.24 \\
\hline & 27 & Well-dying is a natural death without life extension or treatment. & $6.50( \pm 0.755)$ & -1.16 \\
\hline & 23 & Well-dying is a death that leaves property or heritage for children & $2.62( \pm 1.187)$ & -1.34 \\
\hline & 24 & Well-dying is living a healthy life and then dying painlessly. & $4 \cdot 75( \pm 1.908)$ & -1.37 \\
\hline & 28 & $\begin{array}{l}\text { Well-dying is to die at home without being hospitalized for a long } \\
\text { time. }\end{array}$ & $6.75( \pm 0.707)$ & -1.49 \\
\hline & 26 & Well-dying is when people around you die painlessly. & $5.25( \pm 1.488)$ & -1.61 \\
\hline \multirow[t]{5}{*}{$\begin{array}{l}\text { Type3 } \\
(\mathrm{N}=8)\end{array}$} & 28 & $\begin{array}{l}\text { Well-dying is to die at home without being hospitalized for a long } \\
\text { time. }\end{array}$ & $6.75( \pm 0.707)$ & 2.35 \\
\hline & 27 & Well-dying is a natural death without life extension or treatment. & $6.50( \pm 0.755)$ & 2.20 \\
\hline & 26 & Well-dying is when people around you die painlessly. & $5.25( \pm 1.488)$ & 1.40 \\
\hline & 10 & $\begin{array}{l}\text { Well-dying is a death with a sense of time and grace to organize life } \\
\text { and meet peacefully. }\end{array}$ & $4.87( \pm 0.991)$ & 1.00 \\
\hline & 6 & $\begin{array}{l}\text { Well-dying is when people who live are around and are happily leav- } \\
\text { ing. }\end{array}$ & $4 \cdot 37( \pm 1.685)$ & 0.87 \\
\hline
\end{tabular}




$\begin{array}{llll}14 & \text { Well-dying is that my friends are mourning the death } & 3.12( \pm 1.885) & -1.15 \\ 23 & \text { Well-dying is a death that leaves property or heritage for children } & 2.62( \pm 1.187) & -1.18 \\ 7 & \text { Well-dying is to come blessed and return to where you came from. } & 2.87( \pm 1.726) & -1.29 \\ 5 & \text { Well-dying is a safe haven for death. } & 2.37( \pm 0.916) & -1.33 \\ 18 & \text { Well-dying is to live and die without the support of children or others. } & 2.87( \pm 1.807) & -1.49\end{array}$

\section{DISCUSSION}

This study identified the type of subjective perception of well-dying perceived by the elderly and identified its characteristics and found three types: "acceptable death," "preparing death," and "peaceful death." to compare three types and discuss the differences.

\section{Comparison of Type 1 and Type 2}

Comparison of type 1 and type 2 shows that the order of positive statements is as follows: statement No. 21, 'Welldying is to accept the cycle of life called birth, ageing, disease, and death' (point difference 2.586); statement No. 28, 'Well-dying is to die at home without being hospitalized for a long time' (point difference 2.493); statement No. 20, 'Well-dying is to die without regret or tenacity to life' (point difference 2.266). The orders of negative statements are as follows: statement No. 9, 'Well-dying is to die peacefully after short-time disease' (point difference -2.777); statement No. 8 , 'Well-dying is to be liberated from this hard life and to rest' (point difference -2.369 ).

In type 1 , the interviewee who had high factor weight was No. 26 who said, "Well-dying is to devote to religion and leave without fear". The interviewee was the most negative to the statement, "It is not necessary to leave property to offspring, and I will donate it to society." To interviewee No. 28 , well-dying was "prepare for death for oneself, and to die without giving any burden to anybody." The interviewee was the most negative to the statement, "The world after death will be better than this world." To interviewee No. 13 who had high factor weight in type 2, to prepare for well-dying is "to prepare and write will and goods to leave after death in advance." These responses are similar to the findings that well-dying is to accept death in real life ${ }^{10}$.

\section{Comparison of Type 1 and Type 3}

Comparison of type 1 and type 3 shows that the order of positive statements is as follows: statement No. 21, 'Welldying is to accept the cycle of life called birth, ageing, disease, and death' (point difference 2.883); statement No. 20, 'Well-dying is to die without regret or tenacity to life' (point difference 2.386); statement No. 18, 'Well-dying is to die without burdening son and daughter or other people' (point difference 2.082). The orders of negative statements are as follows: statement No. 27, 'Well-dying is to die naturally without life-sustaining treatment' (point difference -2.475); statement No. 9, 'Well-dying is to die peacefully after shorttime disease' (point difference-1.585).

In type 1 , the interviewee who had high factor weight was No. 26 who agreed to statement 21, "Well-dying is to devote to religion and leave without fear". The interviewee was negative to statement No. 8, "Well-dying is to be liberated from this hard life, and to rest' and statement No. 23, "It is not important how other people think of my death." In type 1, the interviewee who had high factor weight was No. 27 said: "Well-dying is to accept death without regretting one's own life." It is similar to the finding ${ }^{10}$ showing that welldying is to accept death and to be liberated from a hard life. 4.3 Comparison of Type 2 and Type 3

Comparison of type 2 and type 3 shows that the order of positive statements is as follows: statement No. 3, 'Welldying is to know that it is time to die, and to prepare for it' (point difference 2.071); statement No. 8, 'Well-dying is to be liberated from this hard life, and to rest' (point difference 1.500); statement No. 14, 'Well-dying is to die peacefully after short-time disease' (point difference-1.585). The negative statement was statement No. 28, 'Well-dying is to die at home without being hospitalized for a long time (point difference-3.848).

In type 2, the interviewee who had high factor weight was No. 13 said that preparation for well-dying is "to prepare will and goods to leave after death in advance." The most positive response of the interviewee was "Well-dying is tp prepare for death up to the end." In type 3, the interviewee who had high factor weight was No. 27 said, preparation for well-dying is "the most important for a dignified death." The interviewee was the most positive to statement 27 and 28 , and said, "Well-dying is to accept natural death." In particular, type 3 was similar to the findings ${ }^{13}$ that old people showed the tendency not to be a physical and financial burden to family members and not to bother those near them.

\section{CONCLUSION}

This research tried to examine subjective perceptions of welldying of old people and divide them into types. As Korean 
old people tend to accept well-dying as destiny religiously and mentally, it is necessary to provide preparatory education for their usual deaths. In critical care, it is also necessary to provide the family with end-of-life care, but it is a pity not to see the end-of-life through limited cotton. For the needs of patients who want to die from their families, a plan is needed to ensure sufficient time with the inpatients and their families in the intensive care unit.

To have well-dying, it is necessary to upgrade family support, preparation for death, and sense of control, and intervention should be given focusing on peaceful death and acceptance of death. You need to help the rest of your family feel positive and comfortable. However, due to the development of modern medicine and social culture that does not accept death, there are some cases where intensive care is provided right before death. In response, the government should communicate with family members the actual contents related to death such as life-long treatment, advance life-long medical treatment, preparation for death, funeral preparation, and suicide writing, and help them prepare for death and death that the elderly want. Education related to death or preparation for death must be continuously tailored to each age group. In particular, health workers should provide guidance and assistance to those who need attention and preparation for death awareness. Recently in Korea, the level of national interest on advance directives has surged upwards, yet the old people who are the age group most intimate to the procedures of advance directives have a very low level of awareness or knowledge. Thus there is a need for the development of an educational program aimed at the provision of sufficient information regarding advance directives. In Korea, interest in dignified death is increasing more recently than insignificant life. Continuous research should be conducted on how to prepare for and think about death that Koreans think, In particular, there is a need for death preparation education to be conducted by age group to maintain dignity in the end of life. This study was conducted to provide basic data for the development of well-dying education programs and the discontinuation of medical treatment in old age by analyzing the recognition type and the characteristics of each type of well-dying for the elderly. It would be meaningful to conduct surveys to old people residing in urban and rural areas and check whether there is any difference between the two groups of people. It would also be meaningful to research old people who are in dying processes and their families.

\section{RECOMMENDATIONS}

First, using a typed checklist for well-dying classified in this study, customized training for each type should be provided. Second, follow-up studies are required to identify the perception of pre-life treatment discontinuities through the characteristics of the type of well-dying classified in this study.
Second, Follow-up study is needed to confirm the perception of the preliminary life-rate difference through the characteristics of each well-dying type classified in this study.

Third, a comparative study is needed on the death perceptions of subjects who have applied for pre-life discontinuation and those who have not.

Acknowledgement: Authors acknowledge the immense help received from the scholars whose articles are cited and included in references of this manuscript. The authors are also grateful to authors / editors / publishers of all those articles, journals and books from where the literature for this article has been reviewed and discussed.

\section{Funding: None}

\section{Conflict of interest: None}

\section{REFERENCES}

1. Kim DR, Lee SH, Ahn SY, Kim YH, Lee CH, Kim KH. A Study on Dying Well Education Needs of the Elderly People. Journal of the Korea Academia-Industrial cooperation Society. 2019;20(9):270-8.

2. Kim MH, Kwon KJ, Lim YO. Study on good death that Korean aged people recognize-blessed death. Korean J.Social Welfare. 2004;56(2):195-213.

3. Moon H, Cha S, Jung S. Effects of a Well-dying Program on Nursing Students. Korean J. Hospice and Palliative Care. 2015 Sep 1;18(3):188-95.

4. Min D, Cho E. Concept analysis of good death in the Korean community. J. Korean Geront. Nur. 2017 Apr 30;19(1):28-38..

5. Lee MS, Kim YJ. Good death recognized by the elderly. J. Korea Cont. Ass.. 2013;13(6):283-99.

6. Yun YH, Rhee YS, Nm SY, Chae YM, Heo DS, Lee SW, Hong YS, Kim SY, Lee KS. Public attitudes toward dying with dignity and hospice. palliative care. Korean J. Hospice and Palliative Care. 2004;7(1):17-28.

7. Han NY, Yoon HJ, Park EW, Cheong YS, Yoo SM. Perception of a Good Death in the Elderly. J. the Korean Aca. Family Med.. 2002 Jun 30;23(6):769-77.

8. Hwang BD, Choi R, Park JW. Medical personnel's awareness and attitudes which affects to writing advanced medical directives. Health and Soc. Sci. 2014;37:25-47.

9. Yoo KJ. Conditions and direction of well-dying from the viewpoint standing on the contemporary cultural context. Korean's. J. East. Phil.. 2008;55:7-43.

10. Lee CH, Ahn SY, Kim YH, Kim KH. Convergence Research on Relationships among the inhibiting factors of Dying Well. J. Korea Convergence Soc. 2019;10(8):37-44.

11. Kang KA. Comparison of meaning in life and death attitude between participants and non-participants in well-dying education. J. Korean Oncology Nursing. 2010 Aug 1;10(2):156-62.

12. Jo KH. The meaning of dignified dying perceived by nursing students. J. Korean Aca. Soc. Nur. Edu. 2010;16(1):72-82.

13. Meesuk Wang, Su Ok Kim. A study on the subjectivity of welldying in Elderly. J. Comm. Healthcare and Devp. 2020;1(1):1-6.

14. Steinhauser KE, Clipp EC, McNeilly M, Christakis NA, McIntyre LM, Tulsky JA. In search of a good death: observations of patients, families, and providers. 2000:825-832 
15. Meier EA, Gallegos JV, Thomas LP, Depp CA, Irwin SA, Jeste DV. Defining a good death (successful dying): literature review and a call for research and public dialogue. Amer. J. Geriatric Psychiatry. 2016 1;24(4):261-71.

16. Choi EJ, Jeong HS. The effect of nursing students' consciousness of biomedical ethics, good death recognition, and selfesteem on the attitude toward withdrawal of life-sustaining treatment. J. Korea Academia-Industrial cooperation Society. 2018;19(5):275-84.

17. An MS, Lee KJ. Awareness of good death and attitudes toward terminal care among geriatric hospital nurses. Korean J. Hospice and Palliative Care. 2014 Sep 1;17(3):122-33.

18. Han NY, Yoon HJ, Park EW, Cheong YS, Yoo SM. Perception of a Good Death in the Elderly. J. Korean Acad. Family Med. 2002 Jun 30;23(6):769-77.

19. Min D, Cho E. Concept analysis of good death in the Korean community. J. Korean Gerontological Nursing. 2017 Apr 30;19(1):28-38.

20. Lee MS, Kim YJ. Good death recognized by the elderly. J. Korea Cont. Asso. 2013;13(6):283-99.

21. Mee-Hye Kim, Kyung-Rim Shin, Mi-Sun Kang, In Kang. Experience in successfully aging elderly in Korea. J. Korea Gerontological Society. 2004;24(2):79-95.
22. Kim SM, Lee YJ, Kim SY. Attributes considered important for a good death among elderly and adults. J. Korea Gerontological Soc. 2003;23(3):95-110.

23. Sunhe Lee, Kyunghee, Chung. A Study of Perceptions among Middle-aged and Older Koreans about Dying Well: Focusing on Typology. J. Korea Gerontological Society. 2019;39(2):305-323.

24. Kim CG. Factors influencing perception of good death among the community-dwelling elderly. The Korean J. hospice and palliative care. 2014 Sep 1;17(3):151-60.

25. Lee Y, Kim PH, Park M, Je NJ. Effects of Well-dying Program on the Death Anxiety, Perception of Good Death, and Readiness for Death-Comparison of Aged and College students. J. Korea Acad. Ind. cooper. Soc. 2019;20(8):514-22.

26. Eun Ja Yeun, T W Kang. Subjectivity of death and dying among the Korean elderly. J of KSSSS. 2019;47(6):5-27

27. Hung Gue Kim. Q Understanding and Application of Methodology, Sogang University Press Culture Research Institute. 1990:40-45.

28. Kae Hwa Jo. The meaning of dignified dying perceived by nursing students. J Korean Acad Soc Nurs Educ. 2010;16:72-82. 